\title{
A prospective study of real-time identification of line of transection in robotic colorectal cancer surgery by ICG
}

\author{
S. P. Somashekhar ${ }^{2} \cdot$ Gangasani Revanth Kumar Reddy $^{1}$ (D) Abhinav Yeshwant Deshpande ${ }^{3}$ K. R. Ashwin ${ }^{2}$. \\ Rohit Kumar ${ }^{2}$
}

Received: 24 November 2019 / Accepted: 25 May 2020 / Published online: 30 June 2020

(C) The Author(s) 2020

\begin{abstract}
Colorectal cancer is the second most common cancer in women and the third most common cancer in men in the world. Surgical resection is the gold standard treatment and minimally invasive surgery remains the standard of care. Anastomotic leakage is one of the most feared postoperative complications in colorectal surgery. Although several factors have been identified as possible causes of anastomotic leakage (i.e., surgical techniques, patient risk factors, suture material or devices), the complete pathogenesis is still unclear. The reported leak rate ranges from 1 to $30 \%$ and increases as the anastomosis is more distal. To date the most widely used methods to assess tissue perfusion includes the surgeon intraoperative visual judgement based on the colour; bleeding edges of resected margins; pulsation and temperature, thereby resulting in either excess or insufficient colonic resection. Earlier studies in colorectal surgery have suggested that assessment of tissue perfusion by the clinical judgment of the operating surgeon underestimated the risk of anastomotic leakage. Indocyanine green (ICG) is a intravenous dye which has shown promise in identifying the bowel vascularity real time. Earlier studies on colorectal cancer have shown that ICG based detection of bowel vascularity is technically possible and has reduced the anastomotic leak rates in $16.7 \%$ of patients. We conducted a prospective study on patients with ICG guided bowel perfusion during robotic colorectal cancer surgery. The method is technically easy, reproducible and safe. This technique has changed the intraoperative decision in $88 \%$ of patients. Larger studies are needed before this can become the standard of care.
\end{abstract}

Keywords Colorectal cancer · Anastomotic leak · Bowel perfusion · ICG

\section{Background}

Colorectal cancer is the second most common cancer in women and the third most common cancer in men in the world [1]. The clinical spectrum is different in India. The mean age at diagnosis is 47 years with male preponderance [2]. Most of the patients have advanced stage at presentation and Signet ring cell histology is predominant [3].

Surgical resection is the gold standard of treatment for colorectal cancer and minimally invasive surgery remains the standard of care [4]. Anastomotic leakage is one of the most feared postoperative complications in colorectal surgery with a reported leak rate ranges from 1 to $30 \%$ and increases as the

Gangasani Revanth Kumar Reddy

revanthgangasani@gmail.com

1 Aware Global Hospitals, Hyderabad, India

2 Manipal Hospitals, Bangalore, India

3 National Cancer Institute, Nagpur, India anastomosis is more distal [5, 6].The reported rate of patients with an anastomotic leak that requires surgical revision ranges from 10 to $35 \%$ with a mortality rate ranging from 6 to $22 \%$ [7].

Although several factors have been identified as possible causes of anastomotic leakage (i.e., surgical techniques, patient risk factors, suture material or devices), the complete pathogenesis is still unclear [8] Poor local tissue oxygenation secondary to inadequate anastomotic vascular perfusion seems to play a key role in the determination of anastomotic viability.

The most widely used method to assess perfusion is a subjective clinical judgement by the surgeon based on pulsation, temperature and bleeding edges resulting in either excess or insufficient colonic resection. However, at least two studies $[9,10]$ have suggested that the clinical judgment of the operating surgeon underestimated the risk of anastomotic leakage in colorectal surgery.

Many methods of assessing vascularity like pulse oximetry, doppler ultrasound of marginal arteries, Laser doppler flowmetry, ultraviolet fluorescence studies, bowel wall contractility, rapid sampling microdialysis were used but with 
limited usage due to lack of reproducibility and practicality $[11,12]$. Indocyanine green (ICG) is a new dye which has shown promise in identifying colonic vascularity [13]. This is a sterile, anionic, water-soluble but relatively hydrophobic, Tri carbocyanine molecule and, once injected into the vascular system, binds to plasma proteins [14].

It becomes fluorescent when excited by near-infrared light and has shown to identify the real-time image of vascularity of colon with a line of transection, thereby decreasing the risk of anastomotic leak and unnecessary excess colonic mobilization. The da Vinci robotic surgical system is integrated with fluorescence imaging (firefly technology). This provides real-time identification of anatomical structures using near-infrared imaging. ICG dye when injected into the tissues binds to plasma proteins and emits an infrared signal when excited by laser light. The camera of the endoscope has an infrared excitation laser $(800 \mathrm{~nm})$ and also has the ability to visualize infrared light $(830 \mathrm{~nm})$ [15].

Earlier studies in colorectal cancer have shown that ICG based detection of bowel vascularity has changed the plan of extensive bowel resection in $30 \%$ to $50 \%$ of patients and also significantly reduced the anastomotic leak rates $[16,17]$. We conducted a single institutional prospective study to identify the feasibility of ICG identification of colonic vascularity and the change of plan of surgical management.

\section{Material/methods}

This was a prospective study done on 50 patients with colorectal cancer satisfying the inclusion criteria and exclusion criteria over a period of twelve months. Patients with biopsyproven colorectal cancer and Colorectal cancer patients post
Neoadjuvant chemoradiation were included in the study with the exclusion of patients with metastatic colorectal cancer and Pregnant or lactating women and patients with known allergy to ICG.

All the patients underwent standard robotic surgery. The inferior mesenteric artery was fully dissected and ligated at its origin preserving the nerves. We chose high ligation because of better lymph node harvest and complete mobilization for resection. There is no unified consensus on the site of ligation and we have followed this in our study for low anterior resection patients. Colonic mobilisation was done in a "medial-to-lateral" approach with high ligation of the main feeding vessels was done. Stapled anastomosis was intra-corporeal in all the cases. After distal transection of the bowel, the point of proximal transection was judged by the team of 3 people consisting of the operating surgeon, assistant surgeon and a fellow in robotic surgery. The point of transection was identified in the vascular segment well above the margin of $5 \mathrm{cms}$ from tumor edge. This point was labelled B. ICG was then injected ( $3 \mathrm{ml}$ of $2.5 \mathrm{mg} / \mathrm{ml}$ ) intravenously and then line of demarcation identified in firefly mode and labelled point $\mathrm{A}$ if moved more than $5 \mathrm{~mm}$ proximal to the original and point $\mathrm{C}$ if moved more than $5 \mathrm{~mm}$ distally. Any change less than $5 \mathrm{~mm}$ remained as point $\mathrm{B}$. The perfusion images were recorded and assessed in real time.

\section{Results}

The results of the study are represented in the flow diagram which shows the total number of patients enrolled in the study were 65 in number of which 15 were excluded and 50 patients were included for the final study.

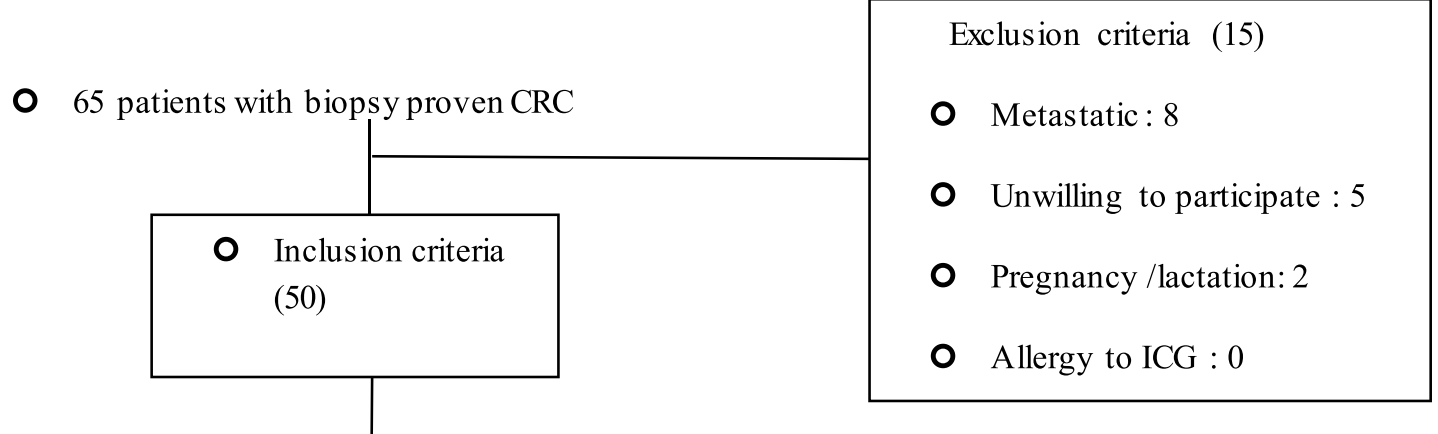


Table 1 Showing patient demographics

\begin{tabular}{ll}
\hline Patient charecteristics & No. of patients \\
\hline Age (years) Median \pm SD & $54.52 \pm 12.6$ years \\
Male & 32 \\
Female & 18 \\
Location & \\
Colon & 6 \\
Rectum & 44 \\
TNM staging & \\
I & 0 \\
II & 3 \\
III & 47 \\
IV & 0 \\
Operative procedure & \\
Sigmoidectomy & 6 \\
Low anterior resection & 44 \\
Illeostomy & 44 \\
Pre-operative chemoradiation & 44 \\
High ligation of IMA & 44 \\
Splenic flexure mobilisation & 44 \\
\hline
\end{tabular}

\section{SHOWING PERFUSED AND NON-PERFUSED SEGMENTS}

\section{AND THE LINE OF TRANSECTION}

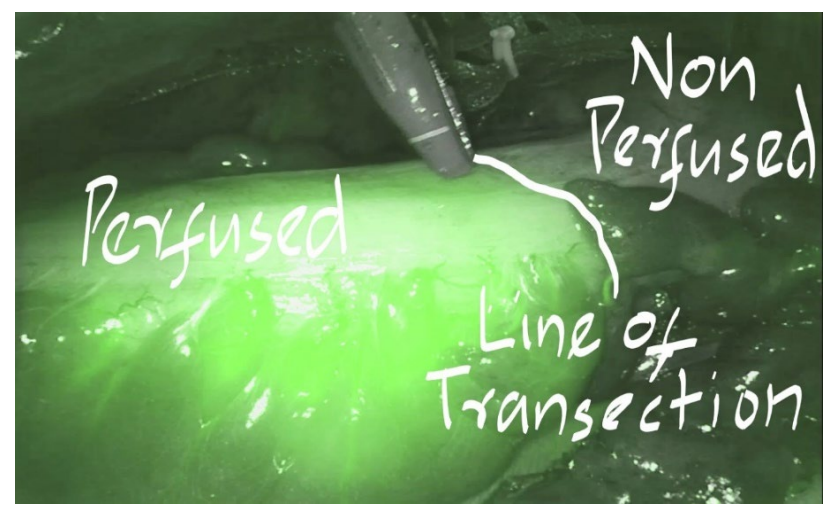

Fig. 1 Showing perfused and non-perfused segments and the line of transection

Firefly technology was used to assess bowel perfusion in all patients. The patient characteristics in the study are shown in Table 1 which shows the mean age of patients was $54.52 \pm 12.6$ years and there were 18 females and 32 males (Figs. 1, 2).

All the rectal cancer patients had a locally advanced disease and received preoperative chemoradiation. 47 patients had stage 3 disease and 3 sigmoid colon patients had stage 2 disease. Six patients had a sigmoid colectomy and 44 patients underwent low anterior resection with sigmoid colon mobilization and ileostomy. There were no intraoperative adverse events or conversion to open surgery. Protective ileostomy was carried out in all low anterior resection patients. There were no side effects related to the injection of ICG. As shown in Table 2, ICG-enhanced fluorescence was detected in $100 \%$ of the cases.

41 patients had a change of plan to distal transection and 3 patients had a change of plan to proximal resection with more than $5 \mathrm{~mm}$ change. Only 6 patients had no change in the surgical plan. There were no anastomotic leaks in all the patients who underwent a change in surgical plan based on intraoperative perfusion assessment by ICG. Reversal of ostomy was performed in the patients after endoscopic evaluation.

\section{Discussion}

Anastomotic failure is the most feared complication of bowel surgery. Vascular perfusion is pivotal for anastomotic integrity of the bowel. Adequate vascular supply of the left colon depends on the patency of the inferior mesenteric artery, the left colic artery and also relies on patency of the middle colic artery and the marginal artery of Drumond and eventually Riolan arcades [24, 25]. Anatomic variations are frequent, and aberrations such as the absence of the middle colic artery or inadequate vascularization of the splenic flexure are frequent (up to 25\%) [26-29].

The vascular perfusion of bowel can be assessed subjectively and objectively. Subjective assessment by visual inspection under white light has been the gold standard and is widely practiced. This method of visual inspection alone has shown to underestimate the vascularity in previous studies [18-20] leading to the removal of either excess colon or less colon. Many methods of objective assessment of bowel perfusion are available which lack reproducibility and are cumbersome [30]. ICG is a intravenous dye which can identify the vascularity of bowel real-time objectively.

Indocyanine green angiography is a more recent development in colorectal surgery. Previous studies in literature by Kawada et al. have shown a 30\% change of plan with ICG and Hellen et al. have shown a 50\% change of plan. Kudszus et al. [21] demonstrated a reduction in risk of surgical revision of $60 \%(7.5-3.5 \%)$ using fluorescence angiography in a case-matched retrospective study. These data have been confirmed by Jafari et al. [22] during roboticassisted laparoscopic rectal surgery.

A recent retrospective case-matched study by Kin et al. [23] on colorectal resection demonstrated that once fluorescence angiography was performed, surgeons decided to change the proximal resection margin alone in $8 / 173$ patients $(4.6 \%)$ but this was not correlated with a significant reduction in the leak rate once compared to the 


\section{SHOWING THE POINTS A, B AND C WITH PERCENTAGE}

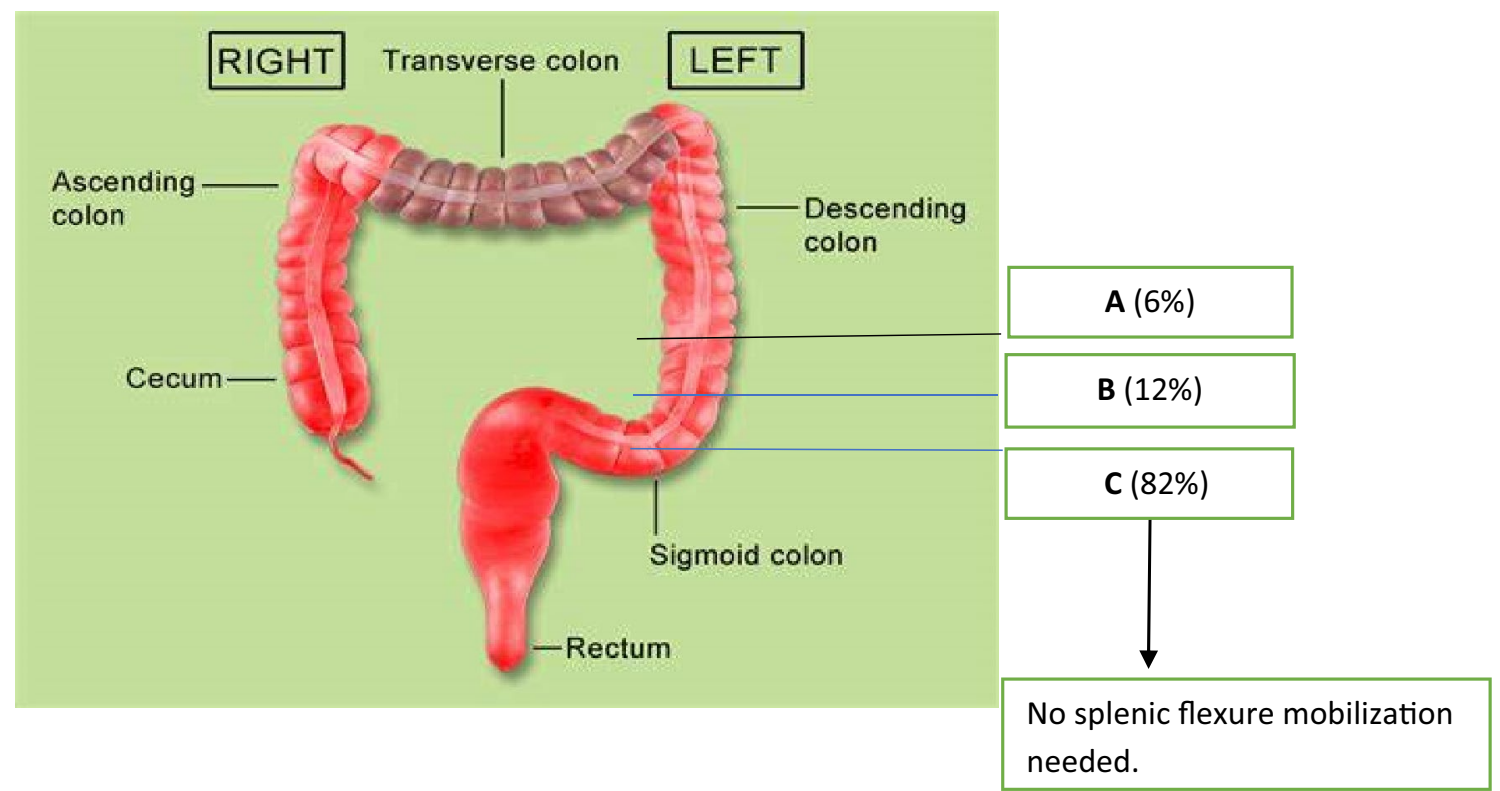

Fig. 2 Showing the points $\mathrm{a}, \mathrm{b}$ and $\mathrm{c}$ with percentage

\section{Conclusion}

Table 2 Showing the results of the study

\begin{tabular}{lr}
\hline Total no of cases & 50 \\
Identification & 50 \\
Line of transection moved proximally $(>5 \mathrm{~mm}$ change $)$ & 3 \\
Line of transection moved distally $(>5 \mathrm{~mm}$ change $)$ & 41 \\
Line of transecteion remained the same $(<5 \mathrm{~mm}$ change $)$ & 6 \\
Change of plan & 44 \\
Conversion to open & 0 \\
Anastomotic leakage & 0 \\
\hline
\end{tabular}

matched group where fluorescence angiography was not performed.

The effect of repeated injections of ICG is not known and has not been investigated [31]. Another drawback is that there is still no strict analytic measure to objectively quantify the signal intensity, and the evaluation of images still depends on the surgeon's judgment.

At least two studies [32, 33] focused on the blood supply assessed using Doppler flowmetry, but although both demonstrated reduced blood flow after resection, it is not clear what is the minimal blood flow to avoid anastomotic leakage [20, 34]. Despite the limitations, ICG-enhanced fluorescence seems to be safe, reproducible, and costeffective to assess colonic and anastomotic perfusion [35].
As per our experience, the injection of ICG provides realtime identification of bowel perfusion after vascular division and shows the line of demarcation between vascular and avascular segments. It has changed the intraoperative decision in $88 \%$ of our patients and amongst whom splenic flexure mobilization could have been avoided in $82 \%$ of patients. It is technically easy, reproducible and safe and larger studies are needed to provide evidence for its routine use in robotic rectal cancer surgery.

Acknowledgements Open access funding provided by Manipal Academy of Higher Education, Manipal. I am grateful to the department of Surgical Oncology, Manipal Hospitals, Bangalore for their valuable help.

Author contributions All authors contributed to the study conception and design. Material preparation, data collection and analysis were performed by Dr. Gangasani Revanth Kumar Reddy. All authors read and approved the final manuscript.

\section{Compliance with ethical standards}

Conflict of interest Authors Dr. GANGASANI REVANTH KUMAR REDDY; Author Dr. SOMASHEKHAR SP; Author Dr. ABHINAV YESHWANT DESHPANDE; Author Dr. ASHWIN KR and Author Dr. ROHIT KUMAR declare that they have no conflict of interest.

Consent to publication Patients signed informed consent regarding publishing their data and photographs. 
Research involving human participants and/or animals All procedures followed were in accordance with the ethical standards of the responsible committee on human experimentation (institutional and national) and with the Helsinki Declaration of 1975, as revised in 2000.

Informed consent Informed consent was obtained from all patients for being included in the study.

Open Access This article is licensed under a Creative Commons Attribution 4.0 International License, which permits use, sharing, adaptation, distribution and reproduction in any medium or format, as long as you give appropriate credit to the original author(s) and the source, provide a link to the Creative Commons licence, and indicate if changes were made. The images or other third party material in this article are included in the article's Creative Commons licence, unless indicated otherwise in a credit line to the material. If material is not included in the article's Creative Commons licence and your intended use is not permitted by statutory regulation or exceeds the permitted use, you will need to obtain permission directly from the copyright holder. To view a copy of this licence, visit http://creativecommons.org/licenses/by/4.0/.

\section{References}

1. Ferlay J, Colombet M, Soerjomataram I, Mathers C, Parkin DM, Piñeros M, Znaor A, Bray F (2019) Estimating the global cancer incidence and mortality in 2018: GLOBOCAN sources and methods. Int J Cancer 144(8):1941-1953

2. Patil PS, Saklani A, Gambhire P, Mehta S, Engineer R (2017) De'Souza A, Chopra S, Bal M Colorectal cancer in India an audit from a tertiary center in a low prevalence area. Indian J Surg Oncol 8(4):484-90

3. Sharma D, Singh G (2017) Clinico-pathological profile of colorectal cancer in first two decades of life: a retrospective analysis from tertiary health center. Indian J Cancer 54(2):397

4. Jayne DG, Guillou PJ, Thorpe H, Quirke P, Copeland J, Smith AM, Heath RM, Brown JM (2007) Randomized trial of laparoscopic-assisted resection of colorectal carcinoma: 3-year results of the UK MRC CLASICC Trial Group. J Clin Oncol 25(21):3061-3068

5. Buchs NC, Gervaz P, Secic M, Bucher P, Mugnier-Konrad B, Morel P (2008) Incidence, consequences, and risk factors for anastomotic dehiscence after colorectal surgery: a prospective monocentric study. Int J Colorectal Dis 23(3):265-270

6. Mirnezami A, Mirnezami R, Chandrakumaran K, Sasapu K, Sagar P, Finan P (2011) Increased local recurrence and reduced survival from colorectal cancer following anastomotic leak: systematic review and meta-analysis. Ann Surg 253(5):890-899

7. Asari SA, Cho MS, Kim NK (2015) Safe anastomosis in laparoscopic and robotic low anterior resection for rectal cancer: a narrative review and outcomes study from an expert tertiary center. Eur J Surg Oncol (EJSO) 41(2):175-185

8. Thornton FJ, Barbul A (1997) Healing in the gastrointestinal tract. Surg Clin N Am 77(3):549-573

9. Karliczek A, Harlaar NJ, Zeebregts CJ, Wiggers T, Baas PC, Van Dam GM (2009) Surgeons lack predictive accuracy for anastomotic leakage in gastrointestinal surgery. Int J Colorectal Dis 24(5):569-576

10. Markus PM, Martell J, Leister I, Horstmann O, Brinker J, Becker $\mathrm{H}$ (2005) Predicting postoperative morbidity by clinical assessment. Br J Surg 92(1):101-106

11. Deeba $\mathrm{S}$. The use of rapid sampling microdialysis in monitoring human bowel and anastomosis ischaemia
12. Córcoles EP, Deeba S, Hanna GB, Paraskeva P, Boutelle MG, Darzi A (2011) Use of online rapid sampling microdialysis electrochemical biosensor for bowel anastomosis monitoring in swine model. Anal Methods 3(9):2010-2016

13. Kawada K, Hasegawa S, Wada T, Takahashi R, Hisamori S, Hida K, Sakai Y (2017) Evaluation of intestinal perfusion by ICG fluorescence imaging in laparoscopic colorectal surgery with DST anastomosis. Surg Endosc 31(3):1061-1069

14. Desmettre T, Devoisselle JM, Mordon S (2000) Fluorescence properties and metabolic features of indocyanine green (ICG) as related to angiography. Surv Ophthalmol 45(1):15-27

15. Lue JR, Pyrzak A, Allen J (2016) Improving accuracy of intraoperative diagnosis of endometriosis: Role of firefly in minimal access robotic surgery. J Min Access Surg 12(2):186

16. Blanco-Colino R, Espin-Basany E (2018) Intraoperative use of ICG fluorescence imaging to reduce the risk of anastomotic leakage in colorectal surgery: a systematic review and meta-analysis. Tech Coloproctol 22(1):15-23

17. Gröne J, Koch D, Kreis ME (2015) Impact of intraoperative microperfusion assessment with pinpoint perfusion imaging on surgical management of laparoscopic low rectal and anorectal anastomoses. Colorectal Dis 17:22-28

18. Seebach L, Bauerfeind P, Gubler C (2010) "Sparing the surgeon": clinical experience with over-the-scope clips for gastrointestinal perforation. Endoscopy 42(12):1108-1111

19. Bruce J, Krukowski ZH, Al-Khairy G, Russell EM, Park KG (2001) Systematic review of the definition and measurement of anastomotic leak after gastrointestinal surgery. Br J Surg 88(9):1157-1168

20. Daams F, Wu Z, Lahaye MJ, Jeekel J, Lange JF (2014) Prediction and diagnosis of colorectal anastomotic leakage: a systematic review of literature. World J Gastrointest Surg 6(2):14

21. Kudszus S, Roesel C, Schachtrupp A, Höer JJ (2010) Intraoperative laser fluorescence angiography in colorectal surgery: a noninvasive analysis to reduce the rate of anastomotic leakage. Langenbeck's Arch Surg 395(8):1025-1030

22. Jafari MD, Lee KH, Halabi WJ, Mills SD, Carmichael JC, Stamos MJ, Pigazzi A (2013) The use of indocyanine green fluorescence to assess anastomotic perfusion during robotic assisted laparoscopic rectal surgery. Surg Endosc 27(8):3003-3008

23. Kin C, Vo H, Welton L, Welton M (2015) Equivocal effect of intraoperative fluorescence angiography on colorectal anastomotic leaks. Dis Colon Rectum 58(6):582-587

24. Gourley EJ, Gering SA (2005) The meandering mesenteric artery: a historic review and surgical implications. Dis Colon Rectum 48(5):996-1000

25. Lange JF, Komen N, Akkerman G, Nout E, Horstmanshoff H, Schlesinger F, Bonjer J, Kleinrensink GJ (2007) Riolan's arch: confusing, misnomer, and obsolete. A literature survey of the connection ( $\mathrm{s}$ ) between the superior and inferior mesenteric arteries. Am J Surgs 193(6):742-8

26. Koizumi M, Horiguchi M (1990) Accessory arteries supplying the human transverse colon. Cells Tissues Organs 137(3):246-251

27. Amonoo-Kuofi HS, El-Badawi MG, El-Naggar ME (1995) Anomalous origins of colic arteries. Clin Anat Off J Am Assoc Clin Anat Br Assoc Clin Anat 8(4):288-293

28. Vandamme JP, Der Schuren V (1976) Re-evaluation of the colic irrigation from the superior mesenteric artery. Cells Tissues Organs 95(4):578-588

29. Lange MM, Buunen M, van de Velde CJ, Lange JF (2008) Level of arterial ligation in rectal cancer surgery: low tie preferred over high tie. A review. Dis Colon Rectum. 51(7):1139-45

30. Hellan M, Spinoglio G, Pigazzi A, Lagares-Garcia JA (2014) The influence of fluorescence imaging on the location of bowel transection during robotic left-sided colorectal surgery. Surg Endosc 28(5):1695-1702 
31. Hope-Ross M, Yannuzzi LA, Gragoudas ES, Guyer DR, Slakter JS, Sorenson JA, Krupsky S, Orlock DA, Puliafito CA (1994) Adverse reactions due to indocyanine green. Ophthalmology 101(3):529-533

32. Cooperman M, Martin JE, Evans WE, Carey LC (1979) Assessment of anastomotic blood supply by Doppler ultrasound in operations upon the colon. Surg Gynecol Obst 149(1):15-16

33. Hajivassiliou CA, Greer K, Fisher A, Finlay IG (1998) Non-invasive measurement of colonic blood flow distribution using laser Doppler imaging. Br J Surg 85(1):52-55

34. Vignali A, Gianotti L, Braga M, Radaelli G, Malvezzi L, Di Carlo V (2000) Altered microperfusion at the rectal stump is predictive for rectal anastomotic leak. Dis Colon Rectum 43(1):76-82
35. PN: 1002223 Rev D 02/17 ,Real time anatomy identification using Near infra red guidance - Fluoresence imaging for davinci Si surgical system, OR compendium guide for clinical speciality , Intuitive Surgical

Publisher's Note Springer Nature remains neutral with regard to jurisdictional claims in published maps and institutional affiliations. 